\title{
Telemedicine Adoption in India: Identifying Factors Affecting Intention to Use
}

\author{
Vanita Singh, Indian Institute of Management, Ahmedabad, India \\ (iD) https://orcid.org/0000-0002-3353-3861 \\ Vedant Dev, Ahmedabad University, Ahmedabad, India \\ (iD https://orcid.org/0000-0002-5247-0800
}

\begin{abstract}
COVID-19 pandemic mandates the transformation of the traditional healthcare delivery model from facility-based to virtual care worldwide. The use of technology in delivering healthcare has always been debated and faces challenges as patients as well as providers are often resistive to change. To date, studies focusing on one's intention to use technology have gained significant research attention. Using the technology adoption model as a research framework, a sample of 336 individuals within the age group of 18-70 years were surveyed via online to understand their intention to use telemedicine. Data were analyzed using structural equation modeling. The findings suggest that perceived ease of use is a significant determinant of one's intention to use telemedicine vis-à-vis its effect on perceived usefulness and attitude towards telemedicine use. The attitude towards telemedicine is significantly affected by privacy concerns and outcome beliefs. The study results have implications for health policymakers and others when implementing telemedicine for today's healthcare delivery.
\end{abstract}

\section{KEYWORDS}

Attitude, COVID-19, Intention to Use, Perceived Ease of Use, Perceived Usefulness, Privacy Concerns, TAM, Telemedicine, Virtual Care

\section{INTRODUCTION}

COVID-19 pandemic has been transforming the traditional healthcare delivery model from facilitybased to virtual care worldwide. Across the globe, healthcare planners and policymakers are racing to adopt virtual healthcare practices as health workers' lives are at stake due to the increased risk of infection spread (Webster, 2020). Massive resistance to the use of technology in health care to ring in virtual care has gradually faded. Yet, the COVID-19 era has significant challenges to overcome. By March 30, 2020, most of the countries, including India, have embraced virtual care and issued guidelines for "telemedical" practices. Fueled by China's and Italy's experience, this shift among healthcare planners and governments in which hospitals are now recognized as the "super-spreader center" for coronavirus or COVID-19 "hot spots" has led to patients being largely restricted from in-person visits but to seek clinical consultative help online so as to limit the spread of Coronavirus among healthcare professionals (Webster, 2020).

Until recently, telemedicine has been promoted to ensure quality health care delivery for rural and remote areas, addressing the shortage of healthcare workers, providing access to continuing medical 
education, enhancing patient education and long-distance monitoring, as well as enabling secondlevel consultations with the super-specialists. A major change that the COVID-19 era has introduced is the push for online consultations even for first-level treatments, that is, primary consultations. The agenda for promoting telemedicine has suddenly shifted from an attempt to "reduce distance barriers via telemedicine" to "maintain distance via telemedicine". The World Health Organization (WHO) defines telemedicine as "the delivery of health-care services, where distance is a critical factor, by all health-care professionals using information and communications technologies for the exchange of valid information for the diagnosis, treatment, and prevention of disease and injuries, research and evaluation, and the continuing education of healthcare workers, to advance the health of individuals and communities" (WHO, 2010, pp.8) ${ }^{1}$.

Post-COVID, WHO mentions "telemedicine" as an essential service for health system strengthening and public health management vis-à-vis the fight against coronavirus. This is not the first when the world has realized the potential of technology use in health care during challenging times. In 1985, the Mexico City earthquake, and in 1988, the Soviet Armenia earthquake, the deployment of telemedicine services via satellite were used to serve the medical needs of affected people (Simpson, 2013). In 2004, India has also used telemedicine services in the Andaman-Nicobar region when a tsunami created a disruption of normal life at a wider scale (Chellaiyan, et al., 2019). Put simply, telemedicine in health care is not new; however, its uptake remains poor (Kissi, et al., 2019). Since the first half of the $20^{\text {th }}$ century, technology use in health care is evidenced via the electrocardiogram (ECG) transmission over telephone lines (WHO, 2010), showcasing the potential to enable virtual consultations. Today, the emergence of wireless broadband and the near-ubiquitous internet use has greatly reduced the implementation barriers to telemedicine services. Yet, the resistance among endusers remains and needs to be researched (Chellaiyan, et al., 2019; Harst, et al., 2019).

The current research aims to study key factors affecting the intention to use telemedicine services. Following the introduction, Section 2 overviews the development of telemedicine in India. The Technology Acceptance Model (TAM) and associated concepts, which provide the underlying theoretical framework for this work, are then presented in Section 3. Whereas Section 4 shifts focus to highlight the research model and hypotheses, Section 5 presents the research methodology. Next, Section 6 showcases the various study results while Section 7 rationalizes the broader understanding and associated implications of the study findings. Finally, Section 8 offers some concluding remarks with insights on the study limitations and directions for future research.

\section{TELEMEDICINE IN INDIA}

Since the mid-2000s, several telemedicine programs, initiated by both public and private sectors, exist in India. In 2001, the first telemedicine pilot in India made headlines when the Indian Space Research Organization (ISRO) along with Apollo Hospitals, a private enterprise, launched a pilot project of linking Apollo Rural Hospital with Chennai's Super-specialty Apollo hospital services. Since then, the premier medical teaching institutes and several corporate hospitals have set up telemedicine centers to extend their services; currently, there are about 400 such telemedicine centers in India (Chandwani \& Dwivedi, 2015).

Some of the positive steps towards telemedicine use in Indian health care includes the establishment of the National Telemedicine Taskforce by the health ministry in 2005, the setting up of telemedicine practice guidelines by the Department of Information and Technology, and the launch of several telemedicine projects with The South Asian Association of Regional Cooperation (SAARC). nation groups and African countries by the India Ministry of External Affairs (Chandwani \& Dwivedi, 2015; Chellaiyan et al., 2019). Significantly, in India, the poor healthcare infrastructure and skewed distribution of specialist services make the country a perfect site for the adoption of telemedicine services. Still, for years, its adoption and uptake have been very slow and low, being restricted largely to secondary and tertiary level care, with most of the projects failing to scale up 
and remaining as pilot projects (Chandwani \& Dwivedi, 2015). More generally, the low uptake of telemedicine services in India has been attributed to barriers at multiple levels, challenged with a failure to involve all stakeholders, especially the target community.

Moreover, the current literature from the Indian context focuses primarily on operational and implementation issues, such as telemedicine laws, reimbursement process, privacy, confidentiality, and security of patient data, insurance, maintaining and upgrading of hardware-software, and broadband connectivity (Chandwani \& Dwivedi, 2015; Ateriya, et al., 2018; Chellaiyan, et al., 2019). To date, India's telemedicine model is largely telecentre-based and focuses on secondary-level specialist consultations (Chandwani \& Dwivedi, 2015). However, guidelines released post-COVID-19 suggests home-based telemedicine and the promotion of primary level teleconsultations.

Importantly, a large-scale adoption of telemedicine requires huge investments. Indeed, its longerterm sustainability would depend entirely on the behavioral intention of its end-users. Hence, this calls for a need to examine the key factors that would affect the adoption of new technology in India's healthcare delivery context. Specifically, this study focuses on identifying such factors affecting the behavioral intention of people to use telemedicine for a primary consultation. Using the theoretical framework of "Technology Adoption Model" (TAM) as proposed by Davis (1989), we examine the relationship between perceived usefulness (PU) of telemedicine, perceived ease of use (PEOU) of telemedicine, attitude towards telemedicine and behavioral intention (BI) to use telemedicine, for the primary level consultation among the Indian population. Additionally, we aim to identify the significant antecedents of these TAM constructs.

\section{THEORETICAL BACKGROUND}

This study draws upon the widely accepted "Technology Acceptance Model" (TAM) as proposed by Davis in 1989. The TAM model is based on the theory of reasoned action, which aimed to understand the behavioral intention (BI) of Information Technology (IT) usage (Ajzen \& Fishbein, 1980). To date, TAM has been profusely validated (Venkatesh \& Davis, 2000; Lee et al., 2003; Holden \& Karsh, 2010; Renny et al., 2013; Teo \& Zhou, 2014; Marangunić \& Granić, 2015; Marakarkandy et al., 2017). It considers the acceptance of technology as a precursor to its use, wherein use is predicted by the attitude towards technology adoption, and attitude is a function of PEOU or perceived ease of use and PU or perceived usefulness (Davis, 1989).

TAM has been further extended as the Unified Theory of Acceptance and Use of Technology (UTAUT) by (Venkatesh, et al., 2003; Venkatesh \& Davis, 2000) through the addition of constructs from social cognitive theory and theory of planned behavior. Four (4) key TAM constructs include: PEOU, PU, attitude towards technology (AT), and BI to adopt the technology. TAM predicts that PEOU would determine PU, both PEOU and PU would determine AT, and PEOU, PU, and AT would determine BI. The TAM and UTAUT literature defines PEOU in terms of the efforts required to use the technology, PU in terms of efficiency and output, AT as an individual's evaluative judgment on dimensions such as good v. bad, harmful, pleasant, and BI as an individual's willingness to perform the target behavior (Venkatesh, 2000; Venkatesh \& Davis, 2000; Lee, et al., 2003; Rho, et al., 2014; Marangunić \& Granić, 2015).

Within the healthcare context, TAM model is still not well researched, despite it having been widely used in other disciplines (Holden \& Karsh, 2010). Perhaps, one reason may be that health IT researchers mainly focus on the design and implementation issues, while scant attention has been given to the BI of end-users (Holden \& Karsh, 2010). A recent review of theories predicting telemedicine use highlights that there is a lack of consensus on which theories (TAM v. UTAUT) are better to explaining telemedicine adoption (Harst, et al., 2019). As UTAUT is relatively new, the focus of our study will be to validate the TAM model in explaining end-users' attitude towards telemedicine adoption in health care and their intention to use it. Further, a major criticism of TAM is the lack of acknowledgment of individual differences (Agarwal \& Prasad, 1999; Legris et al., 2003; Straub, 
2009). In response, we add individual level contextual factors and propose an augmented TAM to explain telemedicine use. The individual-level contextual factors include age, sex, working status, annual family income, use of smartphones, frequency of video calling usage, prior experience of using telemedicine, the ease of using innovations (technology savviness), the experience of waiting in queues while consulting with doctors, the challenge to visit doctor in-person due to having a busy schedule, privacy concerns, the efficacy of telemedicine outcome in comparison to face-to-face meetings, and the self-efficacy in telemedicine use.

\section{RESEARCH MODEL \& HYPOTHESES}

With the aforementioned theoretical background, this study investigates PEOU, PU, attitude towards telemedicine (AT), and individual BI to use telemedicine services. Our main outcome variable is BI, that is equated with the acceptance of technology in the literature as it reliably predicts the actual use when measuring the actual use is challenged (Davis, et al., 1989; Mathieson, 1991). In fact, BI is often considered as an immediate antecedent of the actual behavior.

For our study, PEOU is measured as the ease of (a) telemedicine use; and (b) becoming skillful to use telemedicine. PU is measured in terms of time saving, travel avoidance, rapid diagnosis and treatment initiation. AT is measured via the evaluative judgment for telemedicine use as good, beneficial, and effective for patient care. BI is measured by asking about the users' intention to use telemedicine given that they will need to have the required resources. The literature related to the application of TAM to novel technology adoption in fields such as banking, education, and human resources suggests that PEOU directly influences PU, and both PU and PEOU affect BI to use technology vis-à-vis their effect on the AT (Davis, 1989; Venkatesh \& Davis, 2000; Lee, et al., 2003; Rho, et al., 2014; Marangunić \& Granić, 2015; Dash, et al., 2019; Kissi, et al., 2019). This suggests that people who are more likely to use a newer technology will have a higher BI and a positive AT towards technology use if they find it easy to use (higher PEOU) and useful as well as effective (higher PU). Based on this discussion our first set of hypotheses (H1, H2, and H3) are:

H1: PU mediates the relationship between PEOU and BI.

H2: AT mediates the relationship between PU and BI.

H3: PU and AT mediate the relationship between PEOU and BI.

The studies that have extended the TAM model highlight the role of facilitating conditions in the intention to use newer technology via PEOU (Venkatesh, 2000; Teo \& Zhou, 2014;). The usefulness of a newer technology and its adoption would depend on the dissatisfaction/ difficulties within the current system (Venkatesh, 2003; Pikkarainen et al., 2004; Renny et al., 2013). This drives our hypotheses $H 4 a, b, c, d$ and $H 5 a, b$ :

$H 4 a, b, c, d$ : PEOU mediates the relationship between facilitating conditions (such as, (a) use of smart phone; (b) use of video-calling services; (c) prior use of telemedicine; and (d) ease of using newer technology) and BI.

$H 5 a, b$ : PU mediates the relationship between dissatisfaction with current consultation system (that include, (a) experience of waiting in queues; and (b) the inability to visit doctor due to a busy schedule) and BI.

Past studies related to technology adoption in health care have highlighted the issues of the efficacy of health outcome, privacy concerns, self-efficacy, and facilitating conditions affecting the attitude of physicians as well as patients negatively (Harst, et al., 2019; Hu, et al., 1999; Kissi, et al., 2019). We define privacy concerns as the belief that one's data is not safe while using online 
platforms. The outcome efficacy (TM efficacy) was measured by asking respondents whether they feel that the treatment outcome would not be affected if they use telemedicine instead of face-to-face (ftf) consultation. The facilitating conditions were reflected by the use of smartphones, frequency of video calling, and prior experience of using telemedicine in our study. Further, these variables have consistently been associated with the low uptake of telemedicine in the Indian context (Chandwani $\&$ Dwivedi, 2015; Ateriya et al., 2018). This discussion leads us to our next set of hypotheses (H6a, $H 6 b$, and $H 6 c)$ :

H6a: AT mediates the relationship between privacy concerns and $\mathrm{BI}$; $H 6 b$ : AT mediates the relationship between TM efficacy and BI; and $H 6 c$ : AT mediates the relationship between self-efficacy and BI.

\section{METHODOLOGY}

\subsection{Study Design and Sample}

A self-administered online soft copy questionnaire was designed in two languages, English and Hindi, to collect data via online platforms, namely, Facebook, LinkedIn, Whatsapp, and email. The reliability of both the questionnaires was tested separately on a pre-test sample of 35 respondents. The final questionnaire was modified based on feedback from the participants (pre-test sample) in terms of being simple to comprehend, self-understood, ease of understanding the questions, mobile-friendly appearance, and the time taken to complete the questionnaire. An introduction about telemedicine was included at the top of the questionnaire, followed by consent form prior to asking respondents to begin filling in the survey, that is, only if the participant consents to voluntarily take part in the study. The survey collected information on socio-demographics, the experience of using online platforms, the frequency of making video-calls for work and family, the experience of using telemedicine and their level of satisfaction, the user's perception on PU of telemedicine platforms for primary consultation, the PEOU of the telemedicine technology, the general AT towards telemedicine technology and BI to use telemedicine technology for the first-level consultation with their doctor.

A convenience sample of people aged 18-70 years who have used any of the four afore-specified online platforms were recruited. In 2020, 500 study participants were contacted from May 16 to May 26 via online mode; of these contacts, 430 responded (a response rate of $86 \%$ ). Out of 430 responses received, there were 94 survey forms with missing values which were eventually removed from the study. Thus, our final study sample is 336 respondents. The study was granted ethical approval by our research institutional review board.

\subsection{Measurement}

\subsubsection{Latent Variables}

The survey questionnaire included four validated constructs, PEOU, PU, AT and BI, adapted from previous studies (Davis, 1989; Hu, et al., 1999; Venkatesh, 2000; Rho, et al., 2014; Kissi, et al., 2019) and tailored to telemedicine services. All these constructs were measured with a 5-point Likert scale to quantify the responses from (1-strongly disagree to 5 - strongly agree). All the measures exhibit high reliability, tested via Cronbach's alpha, (above 0.8 ) with our study sample.

- $\quad \boldsymbol{P E O U}$ was measured via a six-item validated scale adapted from (Hu, et al., 1999; Kissi, et al., 2019). The sample items included: "It would be easy for me to consult a doctor via telemedicine"; "It would be easy for me to become skillful in using telemedicine technology". The Cronbach's alpha for PEOU is 0.86 . 
- $\quad \boldsymbol{P} \boldsymbol{U}$ was measured via a five-item validated scale also adapted from (Hu, et al., 1999). The sample items include - "Using telemedicine for consultation would help me save my time", "Using telemedicine would help in quick diagnosis and treatment". The Cronbach's alpha for PU is 0.85 .

- $\boldsymbol{A T}$ was measured via a three-item scale again adapted from (Hu, et al. 1999) and exhibits a reliability score of 0.82 . The sample items include - "Using telemedicine in health care is a good idea".

- $\quad \boldsymbol{B I}$ was measured via a two-item scale adapted from Venkatesh (2000) and exhibits a reliability score of 0.86 . The sample item includes - "Assuming I had access to the required resources, I intend to use telemedicine for consultation".

\subsubsection{Explanatory Variables}

A most salient criticism of TAM has been the ignoring of individual-level differences (Agarwal \& Prasad, 1999) when assessing the adoption of new technology. For this reason, we added sociodemographic variables and individual-level differences related to the use of technology and the experience of offline consultations to identify factors affecting the BI to telemedicine (TM) use.

- A ge: Age, recorded as a categorical variable, ranges from aged 18-25, aged 26-35, aged 36-45, aged 46-55, aged 55-65, to aged 66 and above.

- Education level: This was recorded as a categorical variable, encompassing five groups: 1 - Up to primary level; 2 - Up to secondary level; 3 - Up to senior secondary level; 4 - graduate level; 5 - postgraduate level and above.

- Working Status: Respondents indicated their working status under the following slots: employed, unemployed, student, retired, or self-employed/business.

- Income level: Income level, captured based on annual family income with brackets to include: less than 100k; 100-300k; 400 -1000k; 1000-2000k and greater than 2000k.

- Smartphone_Use: The use of smartphones, captured as a dichotomous variable, was based on whether or not the respondent uses personal smartphone.

- Use of video-calls for other purposes (Freq_VC): Respondents were asked about their frequency of using smartphones for making video-calls for personal or official work, other than consulting a doctor to be recorded as: daily, weekly, monthly, sometimes, and never.

- $\quad$ Prior use of telemedicine (TM Experience): This was recorded as a dichotomous variable, that is, if a respondent has used telemedicine before to consult with a doctor.

- $\quad$ Ease of using new technology (Tech Savvy): This was measured on a 1-5 Likert scale with 1 being extremely difficult and 5 being extremely easy.

- Privacy concern with the use of TM (Privacy Concern): This was captured as a dichotomous variable, asking the respondents if they feel unsafe to use TM in terms of the privacy and confidentiality of their data.

- Efficacy of TM (TM Efficacy): Respondents were asked whether they think that the treatment outcome would not be affected if they use TM instead of $\mathrm{ftf}$ consultation.

- Self-efficacy belief in TM use (Self-efficacy): Respondents were asked if they believe that they can consult a doctor via TM on their own.

- Dissatisfaction with the current model of consultation: We captured dissatisfaction with the current system of general consultation by asking, "Do you find it difficult to visit your doctor due to your busy schedule?" (Busy schedule) and "Do you experience long waiting-queues while visiting your doctor for primary consultation?" (Waiting-queues).

\subsection{Measurement Model}

The fit of our proposed measurement model was tested using AMOS version 22. The fit of a measurement model refers to the degree to which the proposed model is able to represent the empirical 
data (Kline, 2015). As suggested in the literature we have used the following metrics ${ }^{2}$ to test our measurement model i) Comparative Fit Index (CFI) greater than 0.90, ii) Chi-square measure ( $\chi 2 /$ df) less than 3, and iii) Root Mean Square Error of Approximation (RMSEA) less than 0.07 (Kline, 2015). Chi-square test statistic gives the comparison between the hypothesized model and the null model/the perfect model. It is sensitive to sample size (Cangur and Ercan, 2015). CFI compares the fit of a hypothesized model to the fit of a null model and is not sensitive to the sample size. RMSEA is an "index of the difference between the observed covariance matrix per degree of freedom and the hypothesized covariance matrix which denotes the model"

The hypothesized 13-factor model, where each item loads onto their corresponding factors, provided a good fit to the data $(\chi 2=465.52, \mathrm{df}=258$; $\mathrm{RMSEA}=0.05, \mathrm{CFI}=0.95$, TLI $=0.92)$ (Kline, 2015). The confirmatory factor analysis showed that all these latent constructs, including PEOU, PU, AT and BI, have adequate convergent validity with Average Variance Explained (AVE) greater than 0.5 (Malhotra \& Dash, 2011).

\subsection{Analytic Strategies}

In the analysis of latent variables, structural equation modeling (SEM) was used to test the hypotheses. As the data collection from respondents was done in a cross-sectional manner, there was a risk of common method variance (Podsakoff, et al., 2003). To address this, the common latent factor method was used in the measurement model (Lindell \& Whitney, 2001). The values for the latent variables were obtained via data imputation (by regression) on the measurement model using AMOS (Arbuckle, 2013). Thus, the imputed values are common method variance adjusted. Path model relationships were tested via OLS regressions using SPSS version 22 (George \& Mallery, 2018). The multiple regression model fit indices included R-square ${ }^{3}$ and F-statistic ${ }^{4}$. R-square is calculated as the ratio of variance explained by the model to total variance explained. F-statistic is calculated as the ratio of total variance explained by the model to the unexplained variance. Mediation effects were tested using process macro v3.3 (Hayes, 2018).

\section{RESULTS}

\subsection{Sample Characteristics}

- Demographics. Table 1.a displays key characteristics. A majority of our sample (34\%) belonged to the young age group of 26-35 years. Almost $27 \%$ of our study respondents were above 45 years. The sample was balanced in the sex composition as $51 \%$ were females and $49 \%$ were males. $30 \%$ of our sample had graduation degrees while $67 \%$ had completed post-graduation. In terms of working status, $62 \%$ of our study respondents were formally employed, $8 \%$ had their own business, $15 \%$ were students and $8 \%$ were retired. $65 \%$ of our sample reported experiencing long waiting hours during visit to a doctor and $69 \%$ reported finding it difficult to visit a doctor due to their busy schedule.

- Use of TM. $21 \%$ of our study sample have used TM in the past for consulting their doctor, either via voice call, video-call, or WhatsApp chat. The commonest mode reported for TM service was voice call (30\%), followed by WhatsApp chat. In terms of satisfaction with their experience of TM use, $15 \%$ were neither satisfied, nor dissatisfied while $23 \%$ were extremely satisfied. $65 \%$ of our study respondents reported having privacy concerns associated with the use of telemedicine for consultation. Only $33 \%$ feel that telemedicine consultation is as good as face-to-face consultation as captured by TM Efficacy (see Table 1.a). 
Table 1.a Descriptive Statistics

\begin{tabular}{|c|c|c|}
\hline Variable & Mean/ Proportion & Std.Dev. \\
\hline \multicolumn{3}{|l|}{ Age (in years) } \\
\hline $18-25$ & 0.09 & 0.29 \\
\hline $26-35$ & 0.35 & 0.48 \\
\hline $36-45$ & 0.29 & 0.46 \\
\hline $46-55$ & 0.14 & 0.34 \\
\hline $56-65$ & 0.07 & 0.25 \\
\hline 66 and above & 0.07 & 0.24 \\
\hline Sex $=$ Female & 0.51 & 0.50 \\
\hline \multicolumn{3}{|l|}{ Education Level } \\
\hline Up to primary & 0.00 & 0.05 \\
\hline Up to secondary & 0.01 & 0.11 \\
\hline Up to senior secondary & 0.03 & 0.17 \\
\hline Graduate & 0.29 & 0.46 \\
\hline Post-graduate and above & 0.66 & 0.47 \\
\hline Working $=$ Yes & 0.71 & 0.46 \\
\hline Annual Family Income & 3.26 & 1.06 \\
\hline Uses smart phone & 0.99 & 0.11 \\
\hline Prior experience of TM & 0.21 & 0.41 \\
\hline Tech Savvy & 3.95 & 1.16 \\
\hline Has experienced long waiting hours & 0.65 & 0.48 \\
\hline Reported having busy schedule & 0.69 & 0.46 \\
\hline Concerned about Privacy with TM & 0.65 & 0.48 \\
\hline TM Efficacy & 0.33 & 0.47 \\
\hline Self-Efficacy & 0.77 & 0.42 \\
\hline PEOU & 3.88 & 0.77 \\
\hline PU & 3.22 & 0.61 \\
\hline AT & 3.29 & 0.64 \\
\hline BI & 4.02 & 0.88 \\
\hline
\end{tabular}

TM: Telemedicine

For Annual family income (in Indian Rupees): 1 = "< 100K"; 2 = "100-300K"; 3 = "300-1000K"; 4 = "1000-2000K"; 5 = "> $2000 \mathrm{~K}$ ".

For Tech Savvy: 1 = "Extremely difficult"; 2 = "Somewhat difficult"; 3 = "Neither easy nor difficult"; 4 = "Somewhat easy"; 5 = "Extremely easy"

- Correlations. Table 1.b displays the correlations of the variables investigated. The significance of the correlations is given by p-values calculated using a t-distribution ${ }^{5}$ with $n-2$ degrees of freedom. PEOU was positively correlated with smartphone use $(\mathrm{r}=0.35, \mathrm{p}<0.01)$, frequency of video calling $(\mathrm{r}=0.23, \mathrm{p}<0.01)$, TM experience $(\mathrm{r}=0.13, \mathrm{p}<0.01)$, and ease of using new technology (tech-savvy) $(\mathrm{r}=0.29, \mathrm{p}<0.01)$. PU was positively correlated with waiting queue experience $(\mathrm{r}=0.35, \mathrm{p}<0.01)$ and busy schedule $(\mathrm{r}=0.28, \mathrm{p}<0.01)$. AT was negatively correlated with privacy concern $(r=0.36, p<0.01)$, efficacy of TM $(r=0.40, p<0.01)$, and 


\section{Table 1.b Correlations}

\begin{tabular}{|l|c|c|c|c|c|c|c|c|c|c|c|l|l|}
\hline \multicolumn{1}{|c|}{ Variable } & Age & Education & $\begin{array}{c}\text { Working } \\
\text { Status }\end{array}$ & Income & $\begin{array}{c}\text { Online } \\
\text { Use }\end{array}$ & $\begin{array}{c}\text { Freq } \\
\text { VC }\end{array}$ & $\begin{array}{c}\text { Prior } \\
\text { experience }\end{array}$ & $\begin{array}{c}\text { Privacy } \\
\text { concern }\end{array}$ & $\begin{array}{c}\text { Efficacy } \\
\text { belief }\end{array}$ & PEOU & PU & AT & BI \\
\hline Age & & & & & & & & & & & & \\
\hline Education & $-.22^{* *}$ & & & & & & & & & & & \\
\hline $\begin{array}{l}\text { Working } \\
\text { Status }\end{array}$ & -.05 & $.25^{* *}$ & & & & & & & & & & \\
\hline Income & -.01 & $.17^{* *}$ & $.17^{* *}$ & & & & & & & & & \\
\hline $\begin{array}{l}\text { Online } \\
\text { Use }\end{array}$ & $-.35^{* *}$ & $.36^{* *}$ & $.30^{* *}$ & $.17^{* *}$ & & & & & & & & \\
\hline Freq VC & $-.16^{* *}$ & $.16^{* *}$ & .08 & $.21^{* *}$ & $.30^{* *}$ & & & & & & & \\
\hline $\begin{array}{l}\text { Prior } \\
\text { experience }\end{array}$ & -.04 & .03 & .03 & .08 & .09 & $.18^{* *}$ & & & & & & \\
\hline $\begin{array}{l}\text { Privacy } \\
\text { concern }\end{array}$ & -.05 & -.01 & .01 & .07 & .04 & .06 & $.17^{* *}$ & & & & & \\
\hline $\begin{array}{l}\text { Efficacy } \\
\text { belief }\end{array}$ & -.09 & -.05 & .03 & $-.11^{*}$ & .09 & .03 & .02 & $.21^{* *}$ & & & & \\
\hline PEOU & $-.12^{*}$ & $.13^{*}$ & $.18^{* *}$ & .03 & $.11^{*}$ & $.23^{* *}$ & $.13^{*}$ & $.37^{* *}$ & $.42^{* *}$ & $(.89)$ & & \\
\hline PU & -.04 & .05 & $.13^{*}$ & .00 & .05 & $.15^{* *}$ & $.12^{*}$ & $.35^{* *}$ & $.42^{* *}$ & $.92^{* *}$ & $(.85)$ & \\
\hline AT & -.01 & .05 & $.12^{* *}$ & .03 & .00 & $.15^{* *}$ & $.13^{*}$ & $.36^{* *}$ & $.40^{* *}$ & $.90^{* *}$ & $.96^{* * *}$ & $(.82)$ \\
\hline BI & -.09 & $.13^{* *}$ & $.15^{* *}$ & .02 & .07 & $.20^{* *}$ & $.15^{* *}$ & $.35^{* *}$ & $.39^{* *}$ & $.92^{* *}$ & $.87^{* *}$ & $.89^{* *}$ & $(.86)$ \\
\hline
\end{tabular}

Notes: ${ }^{*} p<0.10,{ }^{* *} p<0.05,{ }^{* * *} p<0.01$

Figure 1.

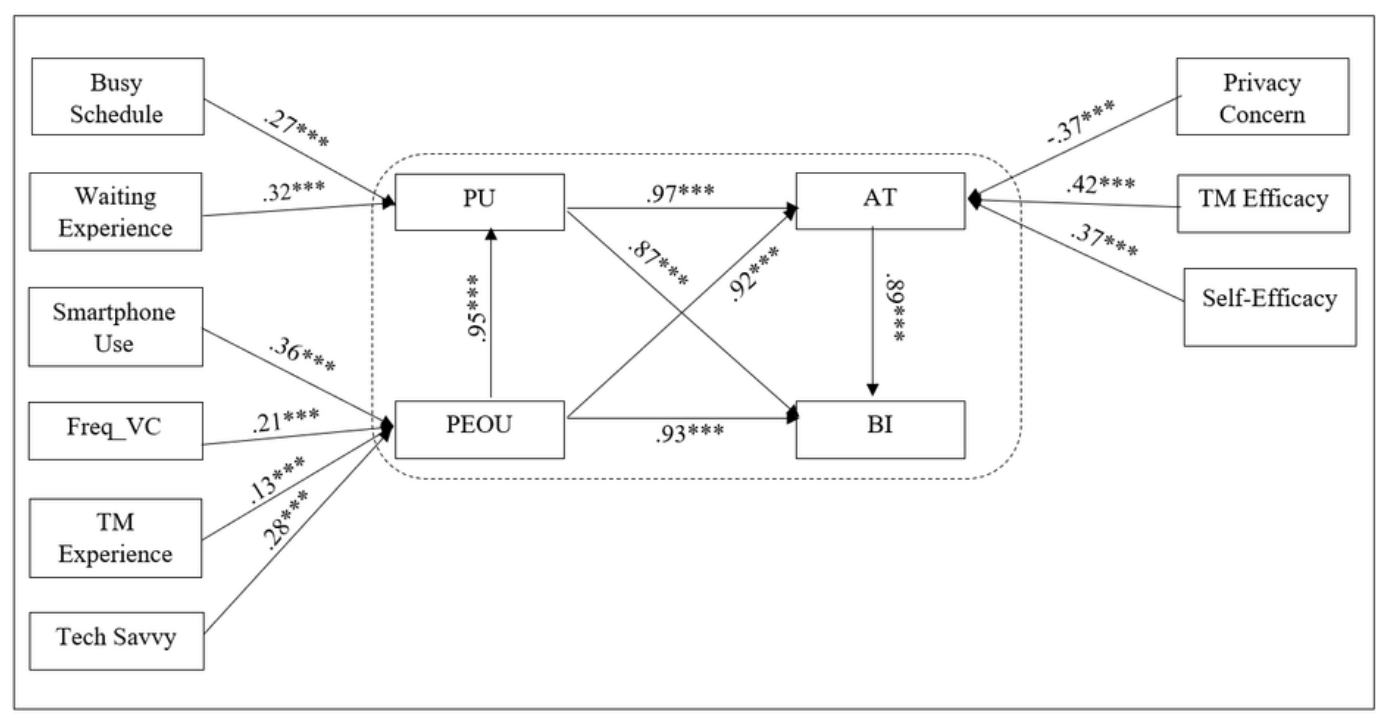


self-efficacy in using TM $(r=0.34, p<0.01)$. The results of the path analysis are shown in Figure 1.

\subsection{Hypotheses Testing}

- TAM Relationships. $H 1, H 2$ and $H 3$ predicted the mediating relationships in TAM. To establish mediation, the indirect effect of the independent variable on the dependent variable via the mediator should be statistically significant (Zhao, et al., 2010). Hence, to test the mediation hypotheses, we had to check for: (1) direct effects of the independent variables on the mediator variables; (2) direct effects of the mediator variables on the dependent variables, and (3) the indirect effects of the independent variables on the dependent variables through the mediator variables. To test these direct effects hypotheses, we regressed the dependent variables with the dependent variables, together with control variables - age, gender, education, working status, and annual family income with results as tabulated.

PEOU had a significant positive relationship with PU (model 1, Table 2: $\beta=0.95, \mathrm{p}<0.01$ ), AT (model 1, Table 3: $\beta=0.92, \mathrm{p}<0.01$ ), and BI (model 1, Table 4: $\beta=0.93, \mathrm{p}<0.01$ ). PU showed a significant positive relationship with AT (model 2, Table 3: $\beta=0.97, \mathrm{p}<0.01$ ) and BI (model 2,

Table 2. Standardized Regression Coefficients for PU

\begin{tabular}{|l|l|l|l|}
\hline \multicolumn{2}{|l|}{ PU } & Model 2 & Model 3 \\
\hline Variables & Model 1 & -.03 & -.01 \\
\hline Age & $0.06^{* * *}$ & .09 & .06 \\
\hline Sex & $0.05 * *$ & .03 & -.01 \\
\hline Education & $-0.06^{* * *}$ & $.13 * *$ & .07 \\
\hline Working Status & -0.02 & -.03 & -.02 \\
\hline Income & -0.01 & & \\
\hline PEOU & $0.95 * * *$ & $.32 * * *$ & \\
\hline Waiting_Exp & & & $.27 * * *$ \\
\hline Busy_Sch & & 336 & 336 \\
\hline Observations & 336 & 0.10 & 0.07 \\
\hline$R^{2}$ & 0.86 & $F(6,329)=7.22 * * *$ & $F(6,329)=5.00 * * *$ \\
\hline$F$ & $F(6,329)=3500.88 * * *$ & \\
\hline Notes: $* p<0.10, * * p<0.05, * * * p<0.01$ & & \\
\hline
\end{tabular}

Table 4: $\beta=0.95, \mathrm{p}<0.01$ ). AT also had a significant positive relationship with BI (model 3, Table 4: $\beta=0.89, p<0.01$ ). Thus, the results support the direct effects criterion of mediation.

Table 5a summarizes the regression results of the direct effects in TAM. The mediator role of PU was found to be significant in the PU-AT relationship (99\% CI: 0.72, 0.79). Likewise, mediation by AT was statistically significant in the PU-BI relationship (99\% CI: 0.42, 0.95). Finally, the serial mediation by PU and AT in the PEOU-BI relationship was found to be statistically significant (99\% 
Table 3. Standardized Regression Coefficients for AT

\begin{tabular}{|c|c|c|c|c|c|}
\hline & $A T$ & & & & \\
\hline Variables & Model 1 & Model 2 & Model 3 & Model 4 & Model 5 \\
\hline Age & $0.09^{* * *}$ & $0.04 * *$ & 0.03 & 0.05 & 0.07 \\
\hline Sex & $0.05^{*}$ & 0.01 & 0.05 & 0.05 & $0.12 * *$ \\
\hline Education & $-0.06^{* *}$ & 0.01 & 0.03 & 0.05 & -0.01 \\
\hline Working Status & -0.04 & -0.02 & $0.11^{* *}$ & 0.09 & $0.10^{*}$ \\
\hline Income & 0.03 & $0.03 *$ & -0.02 & 0.06 & -0.04 \\
\hline PU & $0.92 * * *$ & & & & \\
\hline PEOU & & $0.97 * * *$ & & & \\
\hline Privacy_Concern & & & $-0.37 * * *$ & & \\
\hline TM_Efficacy & & & & $0.42 * * *$ & \\
\hline Self_Efficacy & & & & & $0.37 * * *$ \\
\hline Observations & 336 & 336 & 336 & 336 & 336 \\
\hline$R^{2}$ & 0.82 & 0.93 & 0.13 & 0.17 & 0.12 \\
\hline$F$ & $\begin{array}{l}F(6,329)= \\
2510.43 * * *\end{array}$ & $\begin{array}{l}F(6,329)= \\
6990.04 * * *\end{array}$ & $\begin{array}{l}F(6,329)= \\
90.6^{* * *}\end{array}$ & $\begin{array}{l}F(6,329) \\
=120.19^{* * * *}\end{array}$ & $\begin{array}{l}F(6,329)= \\
80.86^{* * * *}\end{array}$ \\
\hline
\end{tabular}

Table 4. Standardized Regression Coefficients for BI

\begin{tabular}{|c|c|c|c|}
\hline \multirow[b]{2}{*}{ Variables } & \multicolumn{3}{|l|}{$B I$} \\
\hline & Model 1 & Model 2 & Model 3 \\
\hline Age & 0.02 & -0.05 & $-0.08 * * *$ \\
\hline Sex & 0.02 & -0.03 & -0.03 \\
\hline Education & 0.02 & $0.07 * *$ & $0.07 * * *$ \\
\hline Working Status & -0.02 & 0.02 & 0.03 \\
\hline Income & 0.01 & 0.01 & -0.03 \\
\hline PEOU & $0.93 * * *$ & & \\
\hline PU & & $0.87 * * *$ & \\
\hline AT & & & $0.89^{* * *}$ \\
\hline Observations & 336 & 336 & 336 \\
\hline$R^{2}$ & 0.85 & 0.77 & 0.81 \\
\hline$F$ & $F(6,329)=3260.45^{* * *}$ & $F(6,329)=1860.13^{* * *}$ & $F(8,327)=2340.80^{* * *}$ \\
\hline
\end{tabular}




\section{Table 5a. TAM - Direct Effects}

\begin{tabular}{|l|l|l|l|}
\hline Path & $F$ & $R^{2}$ & $\boldsymbol{\beta}$ \\
\hline $\mathrm{PEOU} \rightarrow \mathrm{PU}$ & $F(6,329)=350.88^{* * *}$ & 0.86 & $0.95^{* * *}$ \\
\hline $\mathrm{PU} \rightarrow \mathrm{AT}$ & $F(6,329)=699.04 * * *$ & 0.93 & $0.97 * * *$ \\
\hline $\mathrm{PEOU} \rightarrow \mathrm{AT}$ & $F(6,329)=251.43^{* * *}$ & 0.82 & $0.92^{* * *}$ \\
\hline $\mathrm{AT} \rightarrow \mathrm{BI}$ & $F(6,329)=234.80^{* * *}$ & 0.81 & $0.89 * * *$ \\
\hline $\mathrm{PU} \rightarrow \mathrm{BI}$ & $F(6,329)=186.13^{* * *}$ & 0.77 & $0.87 * * *$ \\
\hline $\mathrm{PEOU} \rightarrow \mathrm{BI}$ & $F(6,329)=326.45^{* * *}$ & 0.85 & $0.93^{* * *}$ \\
\hline Notes: $* p<.10, * * p<.05, * * * p<.01$ & & & \\
\hline
\end{tabular}

\section{Table 5b. TAM - Indirect Effects}

\begin{tabular}{|l|l|l|l|l|l|}
\hline H & Path & $\begin{array}{l}\text { Effect } \\
\text { Size }\end{array}$ & $\begin{array}{l}\text { Confidence } \\
\text { Level }\end{array}$ & LLCI-ULCI & Support \\
\hline H1 & PEOU $\rightarrow$ PU $\rightarrow$ AT & 0.84 & $99 \%$ & $0.72-0.97$ & Supported \\
\hline H2 & PU $\rightarrow$ AT $\rightarrow$ BI & 0.68 & $99 \%$ & $0.42-0.95$ & Supported \\
\hline H3 & PEOU $\rightarrow$ PU $\rightarrow$ AT $\rightarrow$ BI & 0.52 & $99 \%$ & $0.33-0.74$ & Supported \\
\hline & & & & & \\
\hline
\end{tabular}

\section{Table 6. Standardized Regression Coefficients for PEOU}

\begin{tabular}{|l|l|l|l|l|}
\hline \multicolumn{2}{|l|}{ PEOU } & Model 2 & Model 3 & Model 4 \\
\hline Variables & Model 1 & -0.07 & -0.10 & -0.02 \\
\hline Age & -0.07 & 0.01 & 0.02 & 0.08 \\
\hline Sex & 0.02 & 0.06 & 0.08 & 0.04 \\
\hline Education & -0.06 & $0.16^{* * *}$ & $0.16^{* * *}$ & $0.12^{* *}$ \\
\hline Working Status & $0.16^{* * *}$ & -0.06 & -0.03 & -0.04 \\
\hline Income & -0.04 & & & \\
\hline Smartphone use & $0.36^{* * *}$ & $0.21 * * *$ & & \\
\hline Freq VC use & & & $0.13 * *$ & \\
\hline TM experience & & & & $0.28 * * *$ \\
\hline Tech savvy & & 336 & 336 & 336 \\
\hline Observations & 336 & 0.07 & 0.05 & 0.09 \\
\hline$R^{2}$ & $F(6,329)=90.64 * * *$ & $F(6,329)=50.29 * * *$ & $F(6,329)=30.75^{* * *}$ & $F(6,329)=60.69 * * *$ \\
\hline$F$ & $* * 13$ & & \\
\hline Notes: $* p<0.10, * 05, * * p<0.01$ & & & \\
\hline
\end{tabular}


Table 7. Indirect Effects of TAM Antecedents

\begin{tabular}{|l|l|l|l|l|l|}
\hline H & Path & $\begin{array}{l}\text { Effect } \\
\text { Size }\end{array}$ & $\begin{array}{l}\text { Confidence } \\
\text { Level }\end{array}$ & LLCI-ULCI & Support \\
\hline H4a & SPHONE_USE $\rightarrow$ PEOU $\rightarrow$ BI & 2.63 & $99 \%$ & $1.46-3.79$ & Supported \\
\hline H4b & FREQ_VC $\rightarrow$ PEOU $\rightarrow$ BI & 0.13 & $99 \%$ & $0.04-0.21$ & Supported \\
\hline H4c & TM_EXP $\rightarrow$ PEOU $\rightarrow$ BI & 0.25 & $99 \%$ & $0.00-0.49$ & Supported \\
\hline H4d & TECH_SAVVY $\rightarrow$ PEOU $\rightarrow$ BI & 0.20 & $99 \%$ & $0.07-0.33$ & Supported \\
\hline H5a & WAITING_EXP $\rightarrow$ PU $\rightarrow$ BI & 0.49 & $99 \%$ & $0.26-0.73$ & Supported \\
\hline H5b & BUSY_SCHEDULE $\rightarrow$ PU $\rightarrow$ BI & 0.43 & $99 \%$ & $0.18-0.71$ & Supported \\
\hline H6a & PRIVACY $\rightarrow$ AT $\rightarrow$ BI & 0.59 & $99 \%$ & $0.36-0.83$ & Supported \\
\hline H6b & TM_EFFICACY $\rightarrow$ AT $\rightarrow$ BI & 0.67 & $99 \%$ & $0.47-0.86$ & Supported \\
\hline H6c & SELF_EFFICACY $\rightarrow$ AT $\rightarrow$ BI & 0.66 & $99 \%$ & $0.39-0.97$ & Supported \\
\hline & & & & & \\
\hline
\end{tabular}

CI: $0.33,0.74)$. Table $5 \mathbf{b}$ summarizes results of the indirect effects in TAM. Together, it is apparent that the data supports all the predicted relationships in TAM, specifically, $H 1, H 2$ and $H 3$.

- Antecedents to TAM. This set of hypotheses was on the mediation role of TAM constructs PEOU, PU, and AT - between TAM antecedents and BI. Table 7 summarizes the results of the mediation effects with the regression results showing support for $\mathrm{H} 4 a, b, c, d$. All direct effects were found to be significant: PEOU and smartphone use (model 1, Table 6: $\beta=0.36, p<0.01$ ), PEOU and frequency of video calls (model 2, Table 6: $\beta=0.21, \mathrm{p}<0.01$ ), PEOU and prior experience of using TM (model 3, Table 6: $\beta=0.13, \mathrm{p}<0.01$ ), and PEOU and technology savvy (model 4, Table 6: $\beta=0.28, \mathrm{p}<0.01$ ) were statistically significant. Further, PEOU had a significant relationship with BI (model 1, Table 4: $\beta=0.93, \mathrm{p}<0.01$ ). In turn, the mediation role of PEOU was found to be statistically significant for the relationships - smartphone use and BI (99\% CI; 1.46 - 3.79), frequency of video calls and BI (99\% CI; $0.04-0.21)$, prior experience of using TM and BI (99\% CI; $0.00-0.49)$, and technology savvy and BI (99\% CI;0.07 - 0.33).

$H 5 a, b$ were also supported. The relationship between PU and experience of waiting queues (model 2, Table 2: $\beta=0.32, \mathrm{p}<0.01$ ) and busy schedule (model 3, Table 2: $\beta=0.27, \mathrm{p}<0.01$ ) were statistically significant. PU has a significant relationship with BI (model 2, Table 4: $\beta=0.87$, $\mathrm{p}<0.01)$. The mediation role of PU was statistically significant in the relationship between BI and experience of the waiting queues ( $99 \% \mathrm{CI} ; 0.26-0.73$ ), and BI and busy schedule (99\% CI; $0.18-$ 0.71 ) as the confidence interval does not include 0 .

The final set of $H 6 a, H 6 b$ and $H 6 c$ involved the antecedents, privacy concern, the efficacy of TM, and self-efficacy in using TM. These hypotheses were again supported by the test results. For instance, a significant negative relationship was found between AT and privacy concern (model 3, Table 3: $\beta=-0.37, p<0.01$ ), AT and efficacy of TM (model 3, Table 4: $\beta=0.42, p<0.01$ ), and AT and self-efficacy (model 5, Table 3: $\beta=0.37, \mathrm{p}<0.01$ ). The relationship between AT and BI (model 3, Table 4: $\beta=0.89, \mathrm{p}<0.01$ ) was significant. The mediation role of AT in the relationship between BI and privacy concern (99\% CI; $0.36-0.83)$, BI and efficacy of TM (99\% CI; $0.47-0.86)$, and BI and self-efficacy in using TM (99\% CI; 0.39 - 0.97) were also statistically significant. 


\section{DISCUSSION}

A key motivation for this research is to identify the primary factors that determine the use of TM services for routine consultation among the population in India. Drawing from the TAM model and the findings from the related literature (Mathieson, 1991; Venkatesh \& Davis, 2000; Pikkarainen, et al., 2004; Teo \& Zhou, 2014; Marangunić \& Granić, 2015) a research model to guide the current study was developed and tested. Four latent variables, namely, PEOU, PU, AT and BI to use TM, were selected with additional sociodemographic variables and individual-level differences variables incorporated for our study, formulating a series of six (6) hypotheses to test our model via the SEM approach.

The study results supported all of the proposed hypotheses and validated our research model, as evident in our model fit indices (CFI:0.95 and RMSEA:0.05). H1, H2 and $H 3$ tested the mediation effect of PU and AT on the relationship between PEOU and BI. The results indicated that the intention to use TM is significantly affected by PEOU, PU and they both significantly affect attitude towards TM use. This finding supports the validity of the TAM model in explaining the intention to use TM. The existing empirical studies validating the TAM model also report that the intention to use a newer technology is significantly affected by PEOU and PU (Renny et al., 2013; Govender \& Sihlali, 2014; Rho et al., 2014; Teo \& Zhou, 2014).

The PEOU and PU exerted the strongest influence (coefficient $=>0.90, p<0.00$ ) on the intention to use TM in our study sample. Similar findings have been reported from past TAM-related studies to explain intention to use technology for personal use, like internet banking, for education purposes, for online air-ticket bookings (Pikkarainen, et al., 2004; Venkatesh, et al., 2012; Teo \& Zhou, 2014).

For the other hypotheses, we tested antecedents to the TAM model and found that PEOU is a significant mediator between facilitating conditions $(H 4 a, b, c, d)$ and intention to use. The facilitating conditions include the use of smartphones, frequent use of video-call services for other purposes, prior experience of using TM, and ease of using newer technologies. Earlier research also suggested that facilitating conditions act as antecedents of PEOU (Venkatesh, 2000; Shin, 2009).

In our study, the PU of TM is higher for people who find it difficult to consult their doctor either because of their busy schedules and inflexibility in doctor's office hours or because of long waiting queues at doctors' clinics. We term these difficulties as 'dissatisfaction with current consultation system' and argue that people are more likely to use TM if it helps them save time, is flexible to interact with, is easy-to-use, and helps in quick diagnosis and treatment. Attitude towards TM use is significantly affected by privacy concerns, perceived TM outcome efficacy, and self-efficacy in the use of TM. The perceived outcome efficacy has the strongest effect (coefficient: $0.43, p<0.000$ ) on AT. This finding suggests that the doubts about treatment outcome could significantly deter the adoption of TM use. Prior research on technology adoption in health care and other fields has also highlighted the role of trust deficit and privacy concerns with the use of technology (Marakarkandy, et al., 2017; Rho et al., 2014; Kissi, et al., 2019).

The existing studies from India analyzing the adoption of TM highlight the need for increased awareness and acceptance of the technology (Chellaiyan, et al., 2019). Our study results suggest that acceptance of TM would depend largely on the availability of facilitating conditions, the assurance of the confidentiality of medical data, and quality outcome. TM adoption for general consultation can be promoted if users (patients) are ensured that the system is easy-to-use, useful for them, confidential, and the outcome is as efficacious as a face-to-face consultation. Studies using the TAM model to explain the adoption of new technology in fields other than health care also have similar results (Lee, et al., 2003; Pikkarainen, et al., 2004; Marakarkandy, et al., 2017).

Although TM is present in Indian healthcare context since the mid-2000s, it has nonetheless failed to realize its potential (Chandwani \& Dwivedi, 2015; Ateriya, et al., 2018; Chellaiyan, et al., 2019). Moreover, the lack of a legal framework guiding TM practice in India has been identified as a deterring factor (Chandwani \& Dwivedi, 2015; Ateriya et al., 2018). The fight against the COVID-19 
pandemic requires a mandated shift to virtual care. As such, this study has brought timely evidence in identifying the key factors that would affect adoption of virtual care on a large scale.

\section{CONCLUSION}

In conclusion, we observe that research on the adoption of TM will become more crucial as we faced against the mandated changes in the healthcare delivery model in the COVID-19 era. Health planners, policymakers, and implementers need to have evidence-based research data to deliver, plan, and allocate resources. Prior to closing the discussion, we provide brief insights into some of the study limitations and future research directions.

\subsection{Limitations}

Importantly, caution must be used in generalizing the findings of this study. In this study, we have used convenience sampling owing to limited funding and available resources in spite of the need to provide timely evidence for the implementers and planners of healthcare delivery models in India. Moreover, individual-level differences in terms of comfort level with the use of technology are difficult to be factored into the study within a limited time as it requires substantial training and guidance while using TM. The challenge for governments of developing countries, including India, in adopting TM at a wider scale is in ensuring facilitating conditions for the entire population. Owing to the limited availability of bandwidths for high-speed internet connectivity, the quality of the interactions for TM can also be a limiting factor. Finally, the lack of a legal framework for TM practice in India could deter researchers in conducting large-scale TM research unless institutional ethical boards are satisfied with the growing privacy and quality concerns for such services.

\subsection{Future Research Directions}

Looking forward, we believe studies are required using the face-to-face data collection method and on a wider scale with a focus on rural poor. Future research is also needed to compare across cultures, across income groups, gender, across urban-rural, and many more diversities, to acquire a greater understanding of key factors affecting technology adoption in health care. The adoption of virtual care, though in response to COVID-19, is a preparatory step to deal with future epidemics and pandemics and a key challenge to our healthcare system is how best to deliver quality care in a resource-constrained setting. 


\section{REFERENCES}

Agarwal, R., \& Prasad, J. (1999). Are Individual Differences Germane to the Acceptance of New Information Technologies? Decision Sciences, 30(2), 361-391. doi:10.1111/j.1540-5915.1999.tb01614.x

Ajzen, I., \& Fishbein, M. (1980). Understanding attitudes and predicting social behaviour. Prentice-Hall.

Arbuckle, J. L. (2013). Amos 22 User's Guide. SPSS Inc.

Ateriya, N., Saraf, A., Meshram, V. P., \& Setia, P. (2018). Telemedicine and virtual consultation: The Indian perspective. National Medical Journal of India.

Cangur, S., \& Ercan, I. (2015). Comparison of model fit indices used in structural equation modeling under multivariate normality. Journal of Modern Applied Statistical Methods; JMASM, 14(1), 152-167. Advance online publication. doi:10.22237/jmasm/1430453580

Chandwani, R. K., \& Dwivedi, Y. K. (2015). Telemedicine in India: current state, challenges and opportunities. In Transforming Government: People. Process and Policy.

Chellaiyan, V., Nirupama, A., \& Taneja, N. (2019). Telemedicine in India: Where do we stand? Journal of Family Medicine and Primary Care, 8(6), 1872. doi:10.4103/jfmpc.jfmpc_264_19 PMID:31334148

Craig, J., \& Patterson, V. (2005). Introduction to the practice of telemedicine. Journal of Telemedicine and Telecare. doi:10.1258/1357633053430494

Dash, M., Shadangi, P. Y., Kar, S., \& Prusty, R. (2019). A conceptual model for telemedicine adoption: An examination of technology acceptance model. International Journal of Recent Technology and Engineering. 10.35940/ijrte.B1916.078219

Davis, F. D. (1989). Perceived usefulness, perceived ease of use, and user acceptance of information technology. MIS Quarterly: Management. Information Systems.

Davis, F. D., Bagozzi, R. P., \& Warshaw, P. R. (1989). User Acceptance of Computer Technology: A Comparison of Two Theoretical Models. Management Science, 35(8), 982-1003. doi:10.1287/mnsc.35.8.982

George, D., \& Mallery, P. (2018). IBM SPSS Statistics 25 Step by Step: A simple guide and reference. Routledge. doi: $10.4324 / 9781351033909$

Govender, I., \& Sihlali, W. (2014). A study of mobile banking adoption among university students using an extended TAM. Mediterranean Journal of Social Sciences. Advance online publication. doi:10.5901/mjss.2014. $\mathrm{v} 5 \mathrm{n} 7 \mathrm{p} 451$

Hair, J. F., Black, W. C., Babin, B. J., \& Anderson, R. E. (2013). Multivariate data analysis. Pearson Education Limited.

Harst, L., Lantzsch, H., \& Scheibe, M. (2019). Theories predicting end-user acceptance of telemedicine use: Systematic review. Journal of Medical Internet Research.

Hayes, A. F. (2018). Introduction to mediation, moderation, and conditional process analysis: A regressionbased approach. Guilford Press.

Holden, R. J., \& Karsh, B. T. (2010). The Technology Acceptance Model: Its past and its future in health care. Journal of Biomedical Informatics.

Hu, P. J., Chau, P. Y. K., Sheng, L., \& Tam, K. Y. (1999, September). Examining the Technology Acceptance Model Using Physician Acceptance of Telemedicine Technology. Journal of Management Information Systems, 16(2), 91-112. Advance online publication. doi:10.1080/07421222.1999.11518247

Kissi, J., Dai, B., Dogbe, C. S. K., Banahene, J., \& Ernest, O. (2019). Predictive factors of physicians' satisfaction with telemedicine services acceptance. Health Informatics Journal. Advance online publication. doi:10.1177/1460458219892162 PMID:31854222

Kline, R. B. (2015). Principles and practice of structural equation modeling. Guilford Press. 
Lee, Y., Kozar, K. A., \& Larsen, K. R. T. (2003). The Technology Acceptance Model: Past, Present, and Future. Communications of the Association for Information Systems, 12. Advance online publication. doi:10.17705/1CAIS.01250

Legris, P., Ingham, J., \& Collerette, P. (2003). Why do people use information technology? A critical review of the technology acceptance model. Information \& Management, 40(3), 191-204. doi:10.1016/S0378-7206(01)00143-4

Lindell, M. K., \& Whitney, D. J. (2001). Accounting for common method variance in cross-sectional research designs. The Journal of Applied Psychology, 86(1), 114-121. doi:10.1037/0021-9010.86.1.114 PMID:11302223

Malhotra, N. K., \& Dash, S. (2011). Marketing research: An applied orientation. Pearson Publishing.

Marakarkandy, B., Yajnik, N., \& Dasgupta, C. (2017). Enabling internet banking adoption. Journal of Enterprise Information Management, 30(2), 263-294. doi:10.1108/JEIM-10-2015-0094

Marangunić, N., \& Granić, A. (2015). Technology acceptance model: a literature review from 1986 to 2013. Universal Access in the Information Society.

Mathieson, K. (1991). Predicting user intentions: Comparing the technology acceptance model with the theory of planned behavior. Information Systems Research, 2(3), 173-191. doi:10.1287/isre.2.3.173

Pikkarainen, T., Pikkarainen, K., Karjaluoto, H., \& Pahnila, S. (2004). Consumer acceptance of online banking: An extension of the technology acceptance model. Internet Research.

Podsakoff, P. M., MacKenzie, S. B., Lee, J.-Y., \& Podsakoff, N. P. (2003). Common method biases in behavioral research: A critical review of the literature and recommended remedies. The Journal of Applied Psychology, 88(5), 879-903. doi:10.1037/0021-9010.88.5.879 PMID:14516251

Renny, G., Guritno, S., \& Siringoringo, H. (2013, June). Perceived Usefulness, Ease of Use, and Attitude Towards Online Shopping Usefulness Towards Online Airlines Ticket Purchase. Procedia: Social and Behavioral Sciences, 81, 212-216. Advance online publication. doi:10.1016/j.sbspro.2013.06.415

Rho, M. J., Choi, I., \& Lee, J. (2014, August). Predictive factors of telemedicine service acceptance and behavioral intention of physicians. International Journal of Medical Informatics, 83(8), 559-571. Advance online publication. doi:10.1016/j.ijmedinf.2014.05.005 PMID:24961820

Simpson, A. T. (2013). A Brief History of NASA's Contributions to Telemedicine. Nasa.

Straub, E. T. (2009). Understanding technology adoption: Theory and future directions for informal learning. Review of Educational Research, 79(2), 625-649. doi:10.3102/0034654308325896

Teo, T., \& Zhou, M. (2014). Explaining the intention to use technology among university students: A structural equation modeling approach. Journal of Computing in Higher Education, 26(2), 124-142. Advance online publication. doi:10.1007/s12528-014-9080-3

Venkatesh, V. (2000). Determinants of Perceived Ease of Use: Integrating Control, Intrinsic Motivation, and Emotion into the Technology Acceptance Model. Information Systems Research, 11(4), 342-365. Advance online publication. doi:10.1287/isre.11.4.342.11872

Venkatesh, V., \& Davis, F. D. (2000). Theoretical extension of the Technology Acceptance Model: Four longitudinal field studies. Management Science, 46(2), 186-204. doi:10.1287/mnsc.46.2.186.11926

Venkatesh, V., Morris, M. G., Davis, G. B., \& Davis, F. D. (2003). User acceptance of information technology: Toward a unified view. MIS Quarterly: Management. Information Systems, 27(3), 425. Advance online publication. doi: $10.2307 / 30036540$

Webster, P. (2020). Virtual health care in the era of COVID-19. The Lancet.

WHO. (2010). Telemedicine: Opportunities and developments in member States. Report on the second global survey on eHealth Global Observatory for eHealth series -Volume 2 WHO Library Cataloguing-in-Publication Data. https://www.who.int/goe/publications/goe_telemedicine_2010.pdf

Zhao, X., Lynch, J. G. Jr, \& Chen, Q. (2010). Reconsidering Baron and Kenny: Myths and truths about mediation analysis. The Journal of Consumer Research, 37(2), 197-206. doi:10.1086/651257 


\section{ENDNOTES}

World Health Organization (WHO, 2010). Telemedicine Opportunities and Developments in Member States. Available at: https://www.who.int/goe/publications/goe_telemedicine_2010.pdf

For details of measurement model testing metrics please refer (Cangur \& Ercan, 2015)

F-statistic $=$ Mean of Squares for the Model (MSM) / Mean of Squares for the Error (MSE)

$M S M=\sum_{i=1}^{i-n}\left(\hat{y_{i}}-\bar{y}\right) \wedge 2 /$ Degreesoffreedomforthe $\bmod$ el $(p-1)$

$M S E=\sum_{i-1}^{i-n} \wedge\left(y_{i}-\bar{y}\right) \wedge 2 /$ Degreesoferror $(n-p)$

Where $\mathrm{p}$ is the regression parameters and $\mathrm{n}$ is the sample size

F-statistic $=$ Mean of Squares for the Model (MSM) / Mean of Squares for the Error (MSE)

$M S M=\sum_{i=1}^{i-n}\left(y_{i}-\bar{y}\right) \wedge 2 /$ Degreesoffreedomforthe $\bmod \operatorname{lol}(p-1)$

$M S E=\sum_{i-1}^{i-n} \wedge\left(y_{i}-\bar{y}\right) \wedge 2 /$ Degreesoferror $(n-p)$

where $\mathrm{p}$ is the regression parameters and $\mathrm{n}$ is the sample size

5 $t=r \sqrt{n-2 / \sqrt{1-r^{2}}}$ where $\mathrm{r}$ is correlation coefficient and $\mathrm{n}$ is the sample size. 